\title{
Influence of pH in Obtaining Indium Tin Oxide Nanoparticles by Microwave Assisted Solvothermal Method
}

\author{
Fernando Modesto Borges de Oliveira ${ }^{a}$, José Arana Varela ${ }^{b}$, Marcelo Ornaghi Orlandi ${ }^{b *}$
}

\author{
aDepartamento de Química, Universidade Federal de São Carlos, CEP 13565-905, P.O. Box 676, São \\ Carlos, SP, Brazil \\ ${ }^{b}$ Departamento de Físico Química, Universidade Estadual Paulista, CEP 14800-060, P.O. Box 355, \\ Araraquara, SP, Brazil
}

Received: April 25, 2017; Revised: November 17, 2017; Accepted: November 23, 2017

\begin{abstract}
A systematic study about synthesis of $\mathrm{In}_{1-\mathrm{x}} \mathrm{Sn}_{\mathrm{x}} \mathrm{O}_{2}$ (ITO) nanostructured crystals by microwaveassisted solvothermal method is reported. Different solutions using $\mathrm{InCl}_{3} \cdot 4 \mathrm{H}_{2} \mathrm{O}$ and $\mathrm{SnCl}_{4} \cdot 5 \mathrm{H}_{2} \mathrm{O}$ precursors in ethylene glycol solvent were prepared in distinct $\mathrm{pHs}$ (acid and basic ones). The syntheses were performed at $200^{\circ} \mathrm{C}$ using a heating rate of $50{ }^{\circ} \mathrm{C} \mathrm{min}-1$ and soaking time of 30 minutes. All the synthesized powders were characterized by X-ray Diffraction (XRD) and Rietveld refinement to study the phase evolution as a function of $\mathrm{pH}$. The materials synthesized in the $\mathrm{pH}$ ranging between 11.5 and 11.9 were further studied by field emission scanning electron microscopy (FE-SEM) and transmission electron microscopy (TEM) techniques. As ITO materials have many practical applications due to their transparency in the visible spectrum, UV-Vis spectroscopy analysis was performed to obtain the optical band gap and the respective optical window.
\end{abstract}

Keywords: ITO, nanoparticles, Microwave-assisted solvothermal, optical properties.

\section{Introduction}

Transparent and conductive oxides (TCOs) have great technological interest due to the antagonist properties they can present. The indium tin oxide (ITO) composition stands out among other conductive oxides (fluorine-doped tin oxide, antimony tin oxide, aluminum-doped zinc oxide, indium zinc oxide) due to both the high electrical conductivity, and optical transmittance, which can reach up to $90 \%$ in the visible spectrum ${ }^{1-5}$. Therefore, it is easy to find out different kind of applications for TCOs, such as: optoelectronic devices (electrochromic displays, touch and liquid crystal screen, light emission diode, solar cells), resistive films (windshield plane, anti-static coating, and heat mirrors), photothermal converter, composites, gas sensor, and shielding for microwave ${ }^{6-9}$. The synthesis of ITO nanostructures has been reported by several methods, like co-precipitation of precursor metal ${ }^{10,11}$, carbothermal reduction ${ }^{12}$, microwaveassisted hydrothermal and solvothermal ${ }^{13}$, sol-gel ${ }^{14,15}$, organic templates ${ }^{16}$ and microwave-assisted process in solid state ${ }^{17,18}$, and the morphology of obtained materials is highly dependent on the chosen method, enabling to obtain nanoparticles, nanowires, nanorods, and other morphologies. Regarding the microwave-assisted hydrothermal/solvothermal synthesis, it is well known that there is dependence on the $\mathrm{pH}$ of the solution, but there is no detailed study about the $\mathrm{pH}$ range in which it is possible to obtain the ITO crystals.

Synthesis methods using microwave to assist the formation of nanoparticles have attracted great attention due to the

*e-mail: orlandi@iq.unesp.br short time of synthesis and the consequent energy saving. The thermal and non-thermal effects of microwaves on synthesis are still under discussion, but microwave-assisted method promote both dipole rotation and ion conduction ${ }^{19,20}$ allowing it to obtain faster synthesis than conventional hydrothermal/solvothermal methods. One reason is related to the localized heating, generating hot spots ${ }^{21}$. Besides the time of synthesis, another advantage of this method is the lower temperature needed to crystallize materials and no aggressive byproducts. The referred gains have contributed to the popularization of microwave assisted synthesis ${ }^{22}$.

In this context, the proposal of this work consists in a careful study of the $\mathrm{pH}$ influence on the synthesis of ITO crystals obtained by microwave-assisted solvothermal method. Besides, a deep characterization of the structure and morphology was performed on selected samples. This method was chosen because it provides synthesis at low temperatures and homogeneous heating, features that allow the growth of small particles with controlled size and shape ${ }^{23,24}$.

\section{Experimental Methods}

The precursor materials used in the synthesis of ITO crystals were indium chloride tetrahydrate $\left(\mathrm{InCl}_{3} \cdot 4 \mathrm{H}_{2} \mathrm{O}\right.$, Aldrich; $97 \%$ purity); tin chloride pentahydrate, $\left(\mathrm{SnCl}_{4} .5 \mathrm{H}_{2} \mathrm{O}\right.$, Aldrich; $98 \%$ purity) and tetramethylammonium hydroxide

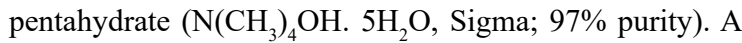
solution was prepared by dissolving $0.7 \mathrm{~g}$ of $\mathrm{InCl}_{3} .4 \mathrm{H}_{2} \mathrm{O}$, and $0.042 \mathrm{~g}$ of $\mathrm{SnCl}_{4} .5 \mathrm{H}_{2} \mathrm{O}$ in $25 \mathrm{ml}$ of ethyleneglycol, meaning it a molar proportion between ions $\mathrm{In}^{3+}$ and $\mathrm{Sn}^{4+}$ of $5 \%$. This 
solution was homogenized by mechanical stirring at $80{ }^{\circ} \mathrm{C}$, in a similar process described by Hammarberg ${ }^{25}$. Another alkaline solution was prepared by dissolving the appropriate amount of $\mathrm{N}\left(\mathrm{CH}_{3}\right)_{4} \mathrm{OH} .5 \mathrm{H}_{2} \mathrm{O}$ in $2 \mathrm{~mL}$ of deionized water. After reaching $80^{\circ} \mathrm{C}$, this alkaline solution was slowly dripped in the solution with the precursor ions until obtaining the desired $\mathrm{pH}$, which is listed in Table 1. Although the $\mathrm{pH}$ gap is small to differentiate some samples, it is important to note that mass of base used to reach that $\mathrm{pH}$ is not negligible. Then, the solution with desired $\mathrm{pH}$ was transferred to a Teflon container with volume of $100 \mathrm{ml}$, which was inserted into a reaction cell adapted to fit a conventional microwave oven designed for this kind of synthesis ${ }^{24}$. The syntheses were performed at $200{ }^{\circ} \mathrm{C}$ with heating rate of $50{ }^{\circ} \mathrm{C} \mathrm{min}{ }^{-1}$, and $30 \mathrm{~min}$ at maximum temperature.

Table 1. Samples' labels, the $\mathrm{pH}$ at each sample was synthesized and the $\mathrm{N}\left(\mathrm{CH}_{3}\right) 4 \mathrm{OH} .5 \mathrm{H}_{2} \mathrm{O}$ mass necessary at syntheses.

\begin{tabular}{ccc}
\hline Sample & $\mathrm{pH}$ & Mass $(\mathrm{g})$ \\
\hline 1 & 5.2 & 1.269 \\
2 & 11.1 & 1.812 \\
3 & 11.5 & 1.914 \\
4 & 11.5 & 1.937 \\
5 & 11.6 & 1.960 \\
6 & 11.8 & 2.050 \\
7 & 11.9 & 2.130 \\
8 & 12.2 & 2.560 \\
\hline
\end{tabular}

After the syntheses, the suspensions were centrifuged and the precipitated particles were washed three times with alcohol ethylic to eliminate any surface residues. Finally, samples were oven dried at $80{ }^{\circ} \mathrm{C}$ before being further characterized. All samples were studied by X-ray diffraction (XRD, Rigaku, model RINT 2000), using $\mathrm{Cu} K \alpha$ radiation, in the $2 \theta$ range from $10^{\circ}$ to $70^{\circ} 26,27$. Morphological and structural characterizations of the selected samples were performed by transmission electron microscopy (TEM; Philips, model CM200) operated at $200 \mathrm{kV}$, and field emission scanning electron microscopy (SEM; JEOL, model 7500F). UV-Vis measurements were obtained from powdered samples by diffuse reflectance method in the range from $320 \mathrm{~nm}$ to 900 $\mathrm{nm}$ with $2 \mathrm{~nm}$ step using Cary $5 \mathrm{G}$ spectrophotometer (Varian, USA). Infrared spectra of powder were measured on Bruker Vertex 70 FTIR spectrometer equipped with Platinum ATR (Attenuated Total Reflectance) accessory. The spectra were recorded between $400 \mathrm{~cm}^{-1}$ and $4000 \mathrm{~cm}^{-1}$.

\section{Results and Discussion}

To understand the $\mathrm{pH}$ behavior as a function of added base, a titration solution having the precursors' ions was performed, as shown in Figure 1. Keeping the precursor solution stirring at $80{ }^{\circ} \mathrm{C}$, the alkaline solution of $\mathrm{N}\left(\mathrm{CH}_{3}\right)_{4} \mathrm{OH} .5 \mathrm{H}_{2} \mathrm{O} 2.5 \mathrm{M}$ was added at a constant flow of $25 \mu \mathrm{L} \cdot \mathrm{min}^{-1}$. From Figure 1

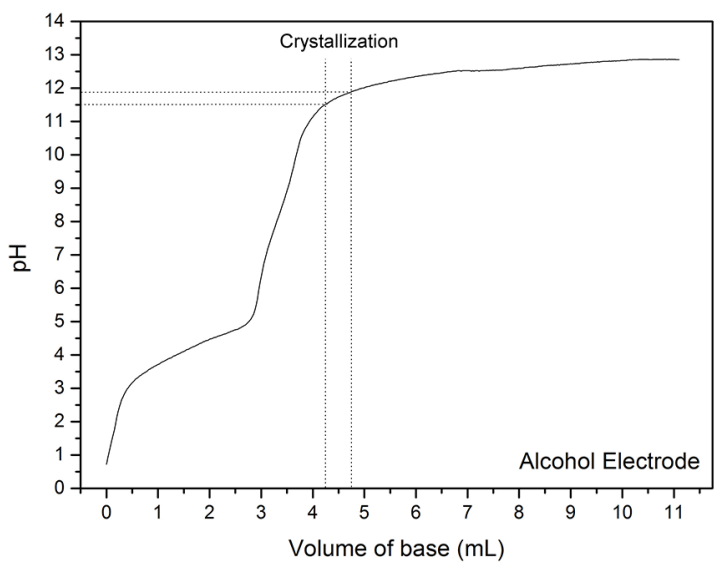

Figure 1. Titration curve of precursor solution with $2.5 \mathrm{M}$ of $\mathrm{N}\left(\mathrm{CH}_{3}\right)_{4} \mathrm{OH} .5 \mathrm{H}_{2} \mathrm{O}$

the titrated solution is kept acid until the added base achieve the volume of $3,7 \mathrm{ml}$. In the alkaline range, $\mathrm{pH}$ increases fast until a volume of $4.2 \mathrm{ml}$, then reaching asymptotically the $\mathrm{pH}$ 13. Using this calibration curve, it is possible to know the amount of base necessary for synthesis at any $\mathrm{pH}$; for instance, a base volume of $4.20 \mathrm{~mL}$ means the synthesis with $\mathrm{pH} 11.47$, and this volume times $2.5 \mathrm{M}$ results in $1.05 .10^{-2}$ moles and, consequently, $1.903 \mathrm{~g}$ of $\mathrm{N}\left(\mathrm{CH}_{3}\right)_{4} \mathrm{OH} .5 \mathrm{H}_{2} \mathrm{O}$. This base has high water solubility, and its mass can be dissolved in amounts as small as $2 \mathrm{~mL}$, which was established as the volume to solubilize the mass of base.

It is important to note that the volume of water determines the pressure of synthesis once the water's boiling point is $100{ }^{\circ} \mathrm{C}$ and the synthesis is carried out at $200{ }^{\circ} \mathrm{C}$. Besides, by controlling the synthesis conditions and time of reaction it was possible to decrease the reaction time in four times when compared to other synthesis ${ }^{25}$. Comparing with a hydrothermal method using infrared heating, which needs $12 \mathrm{~h}$ after calcination in order to crystallize the material ${ }^{28}$, the microwave method is much faster and produces less byproducts.

Figure $\mathrm{S} 1$ shows that synthesized powders have different colors, indicating that $\mathrm{pH}$ plays an important role in the ITO synthesis. Samples 1, 2 and 8 resulted in a white material while samples 3 to 7 resulted in colored (greenish) materials, which means materials with different phases or altered In to Sn ratio.

The structure of synthesized materials was studied by $\mathrm{XRD}$, and the diffractograms are illustrated in Figure 2. Figure 2a presents the XRD plots of samples 1, 2 and 8, and the absence of well-defined peaks is characteristic of solids without long-range order. The shoulders present in Figure 2 a cannot be associated to any known ITO peak. These samples may be related to some amorphous intermediate compound generated by reaction of chemical precursors once they come out as crystalline ITO particles after calcination. In this work the main focus will be on samples crystallized without further calcination. 

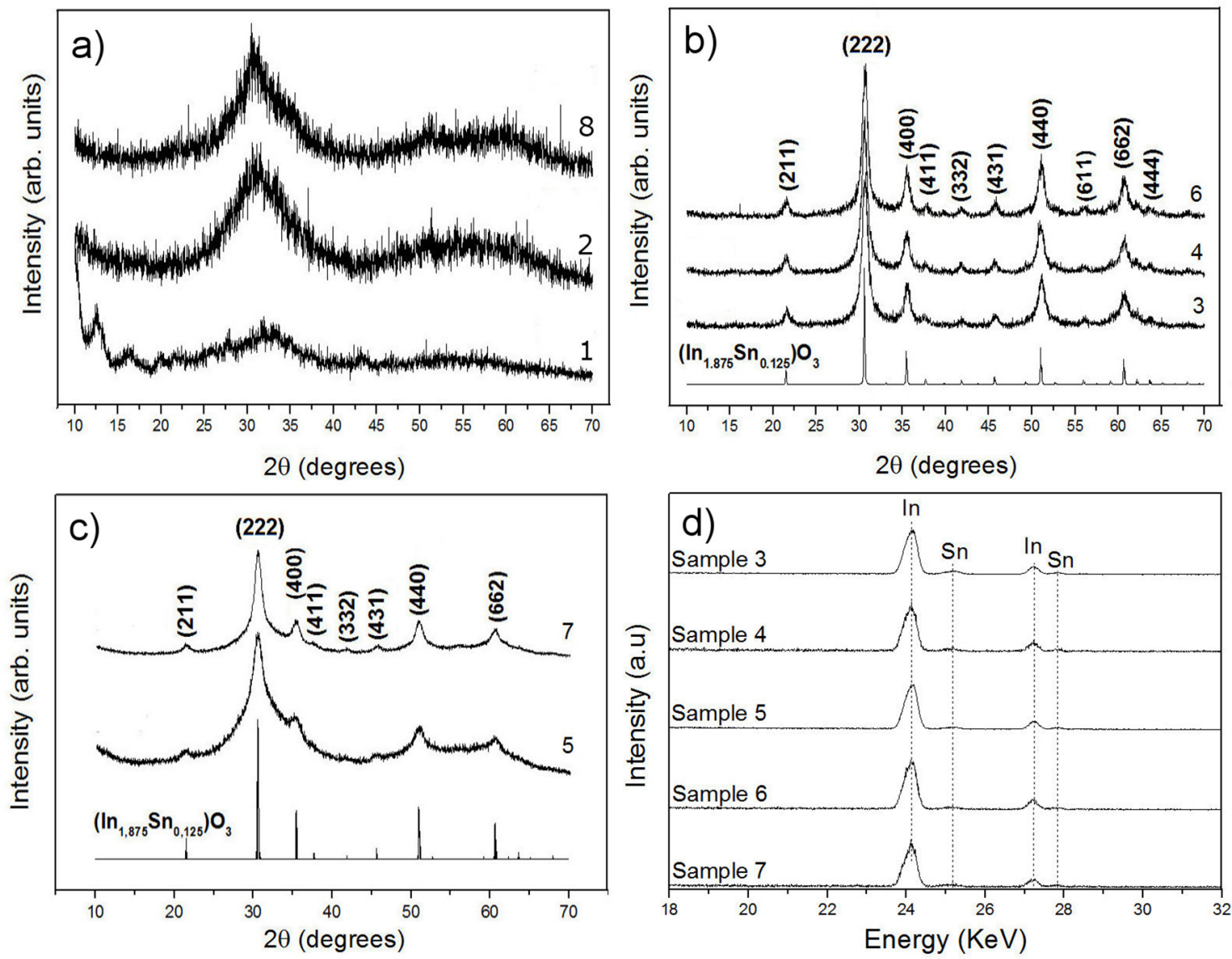

Figure 2. a-c) X-ray diffraction pattern of the synthesized powders. Materials were grouped by phase similarity. The indium tin oxide phase corresponds to the JCPDS card \# 89-4597. Figure d) displays EDS analysis of samples that exhibited crystallinity.

Table 2. Rietveld refinement parameters obtained from X-ray diffraction data from samples 3 to 7.

\begin{tabular}{|c|c|c|c|c|c|c|}
\hline Samples & & 3 & 4 & 5 & 6 & 7 \\
\hline \multirow{2}{*}{$\begin{array}{c}\text { Cation } b \\
x=y=z=0.25\end{array}$} & $\mathrm{U}_{\text {iso }}(\AA)$ & 0.00481 & 0.00481 & 0.00481 & 0.00481 & 0.00481 \\
\hline & $\mathrm{Sn}^{4+}$ fraction & 0.0000 & 0.0250 & 0.0000 & 0.025 & 0.0000 \\
\hline \multirow{2}{*}{$\begin{array}{c}\text { Cation d } \\
\mathrm{x}=\mathbf{0 . 4 6 7 3 0} \mathrm{y}=\mathbf{0} \mathrm{z}=\mathbf{0 . 2 5}\end{array}$} & Uiso $(\AA)$ & 0.00393 & 0.00393 & 0.00393 & 0.00393 & 0.00393 \\
\hline & $\mathrm{Sn}^{4+}$ fraction & 0.0280 & 0.0250 & 0.049 & 0.024 & 0.047 \\
\hline \multirow{2}{*}{$\begin{array}{c}\text { Structural Oxygen } \\
\mathrm{x}=0.38990 \mathrm{y}=0.15470 \\
\mathrm{z}=\mathbf{0 . 3 8 2 1 0}\end{array}$} & $\mathrm{U}_{\text {iso }}(\AA)$ & 0.00633 & 0.00633 & 0.00633 & 0.00633 & 0.00633 \\
\hline & fraction & 0.710 & 0.999 & 0.854 & 0.953 & 0.690 \\
\hline \multirow{2}{*}{$\begin{array}{l}\text { Interstitial Oxygen } \\
\qquad x=y=z=0.125\end{array}$} & $\mathrm{U}_{\text {iso }}(\AA)$ & 0.00633 & 0.00633 & 0.00633 & 0.00633 & 0.00633 \\
\hline & fraction & 0.404 & 0.010 & 0.817 & 0.169 & 0.497 \\
\hline \multirow{2}{*}{ Refinement } & $\mathrm{R}_{\mathrm{Bragg}}(\%)$ & 3.71 & 4.97 & 2.74 & 1.71 & 4.70 \\
\hline & $\chi^{2}$ & 4.37 & 4.45 & 3.61 & 2.10 & 4.75 \\
\hline Unit Cell & a $(\AA)$ & 10.56 & 10.13 & 10.93 & 10.14 & 10.99 \\
\hline Crystallite Size & $(\mathrm{nm})$ & 3.8 & 7.1 & 1.1 & 9.6 & 2.9 \\
\hline
\end{tabular}

Figure $2 \mathrm{~b}$ shows the XRD patterns of samples 3,4 and 6 , presenting well-defined peaks which were fully indexed by indium tin oxide phase (JCPDS card\# 89-4597). Samples 5 and 7, presented in Figure 2c, can also be indexed by the ITO phase, but peaks are broader and have lower intensity, indicating a poorer degree of crystallinity or small nanocrystalline structures. Both indium oxide and indium tin oxide have very similar structures, making it difficult to separate them in the XRD pattern. In order to prove that ITO samples were obtained, the energy dispersive X-ray 


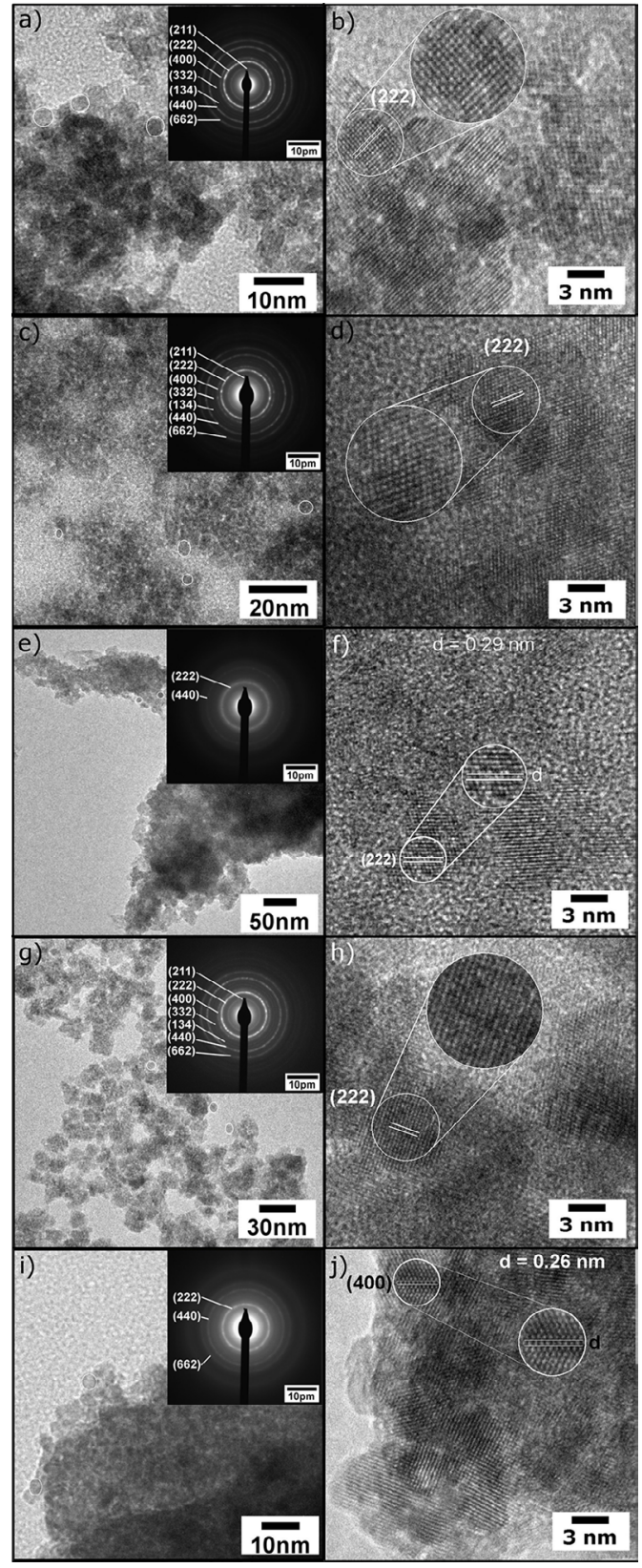

Figure 3. This image is a compilation composed by TEM, HRTEM, and SAD analyses. The left column is showing TEM and SAD figures and the right column shows the HRTEM images. Figure a) and b) belongs to sample 3, c) and d) to sample $4, \mathrm{e}$ ) and f) to sample $5, \mathrm{~g}$ ) and h) to sample 6 and i) and j) to sample 7 . spectrometry (EDS) analyses were performed, and the obtained spectra (Figure 2d) confirm that samples 3 to 7 present both In and Sn atoms in the structure.

Rietveld refinements of XRD data from samples 3 to 7 were performed using GSAS II software ${ }^{29}$, and the parameters obtained from refinements are summarized in Table 2. By comparing the structural values, we found that the lattice parameter of samples 5 and 7 are larger than the other samples, meaning that a more distorted structure was produced, which agrees with the wide and low intensity peaks obtained. As a consequence, these samples present the lowest values of crystallite size. Besides, by analyzing in detail the refinement parameters, it is possible to note that samples 5 and 7 have $\mathrm{Sn}^{4+}$ preferably in $d$ site and a larger amount of interstitial oxygen. In practical terms, peculiarities such as $d$ site occupancy and interstitial oxygen are responsible for its biggest unit cell. Furthermore, samples 4 and 6 seem to be the most stable ones since they have a close distribution of $\mathrm{Sn}^{4+}$ in sites $b$ and $d$, exhibiting lower amount of interstitial oxygen ${ }^{30}$.

Correlating the XRD results with the tritation curve it is possible to infer that the range where the crystallization of ITO nanoparticles is favored after microwave irradiation. Results show that slightly alkaline medium aims crystallization since it occurs after the last equivalence point around $\mathrm{pH}$ 10. The high hydroxide ion concentration is harmful to crystallization and the same is valid for the acid medium.

FEG-SEM images of crystalline samples are depicted in Figure S2. The morphological characteristics of samples are similar, presenting aggregated spherical nanoparticles. By SEM images, the samples 5 and 7 also seem to contain traces of organic waste. The aggregates presented in sample 5 are bigger than the aggregates of samples 3, 4 and 6 indicating some organic residue gluing nanoparticles. For sample 7, a more detailed study reveals plates like morphology similar to the ones observed in polymers, indicating this sample still presents organics. Due to the small size of particles observed by SEM, a more detailed morphological study was performed by TEM (Figure 3). It is possible to note that all samples have particles with diameter smaller than $10 \mathrm{~nm}$, in agreement with Rietveld results. A representative number of particles belonging to samples 3,4 and 6 were counted in order to obtain the distribution of particles diameter and the respective histograms are displayed in Figure 4. The presence
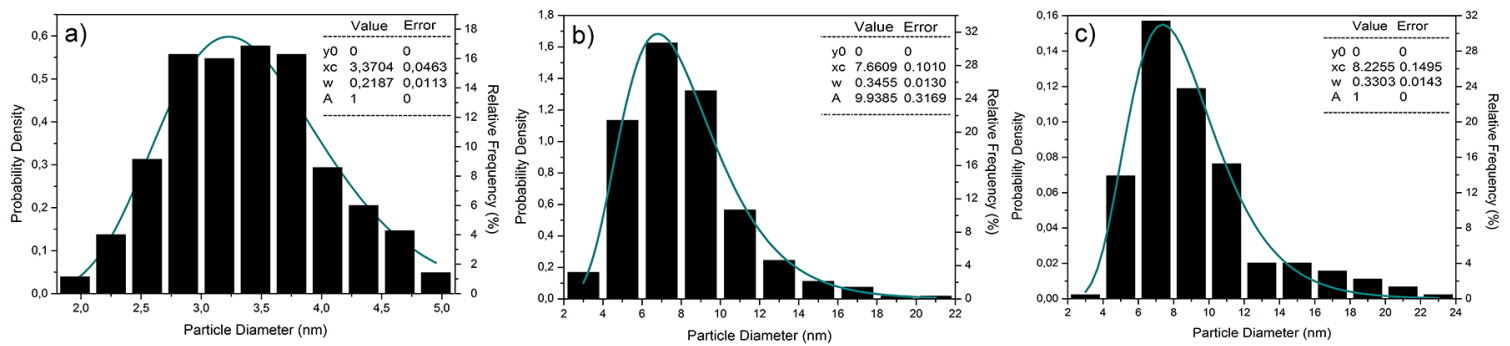

Figure 4. Particle diameter size distribution and probability density of the samples a) 3, b) 4 and c) 6 . Lognormal function was used to represent the particle distribution. 


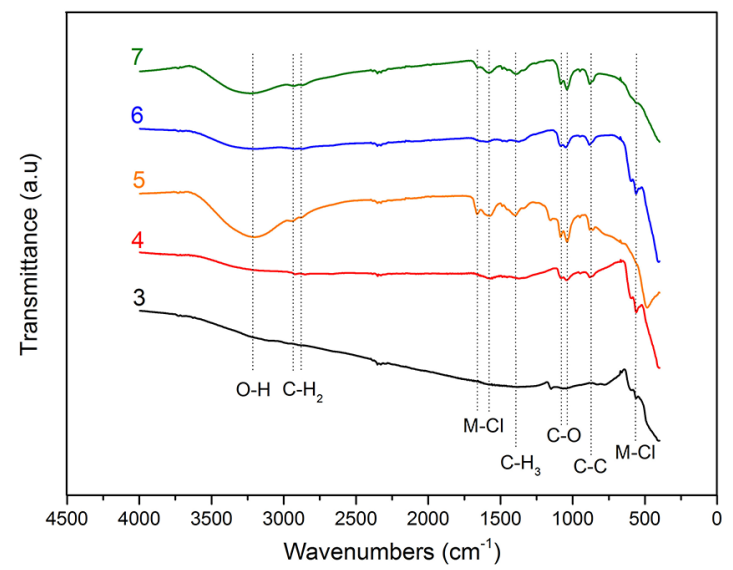

Figure 5. ATR-FTIR of samples 7 to 3, organic band absorption corresponds to ethylene glycol whereas $\mathrm{M}-\mathrm{Cl}$ bands are metal chlorides from precursors.

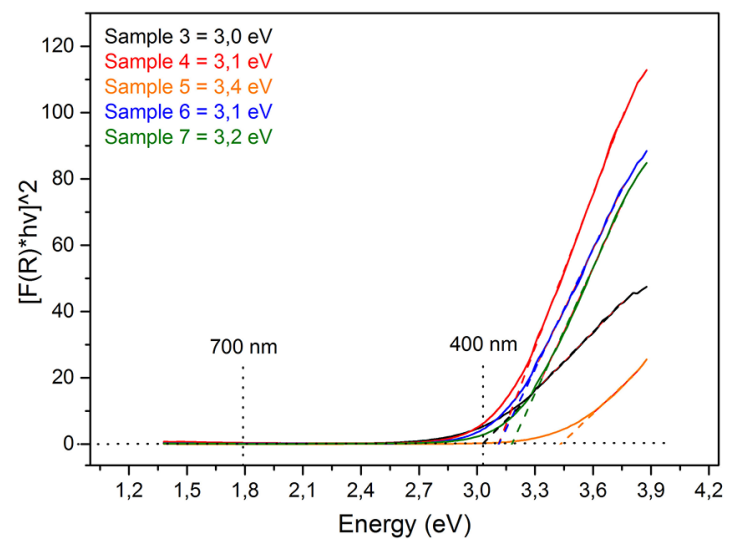

Figure 6. Determination of optical band gap of samples 3 to 7 by drawing a line at $[F(R) h v]^{2}=0$.

of residues and high aggregation degree of the particles belonging to samples 5 and 7 made it impossible to count a significant number of particles to produce a histogram.

A detailed interpretation of HRTEM images was performed by detaching a set of ten atomic planes in some particles. The shown nanoparticles of samples 3 to 6 presented the same distances, with interplanar distance of $2.9 \AA$, which is related to the (222) plane of ITO phase. This plane is the one with maximum diffraction intensity for the ITO structure, so it is easier to observe them in the HRTEM images. For sample 7, different from the previous ones, the crystalline plane observed was the (400), with interplanar distance of $2.6 \AA$. The difference between the planes observed in the HRTEM images has no correlation to any other characteristic of the material since it is an exclusive orientation of particle in the taken image.

The selected area diffraction (SAD) pattern reveals the existence of concentric rings emphasizing the polycrystalline nature of samples, and all the reflection planes are in agreement with the XRD results. The numbers in parentheses associated to each ring are the Miller indices of the respective set of planes. All the atomic planes were indexed as belonging to the ITO phase and there is no secondary phases Samples 5 and 7 presenting wider rings, which is in agreement with the XRD results and was explained based on Rietveld refinement parameters and the presence of organics. Based on the electron microscopy images and the diameter histogram it was possible to infer that the average particle size increases by increasing the $\mathrm{pH}$ of the synthesis. The average diameter of particles for sample 3 is $3.4 \mathrm{~nm}$, and calculating the area under the curve in the range from 2 to $4.5 \mathrm{~nm}$ we conclude that $90 \%$ of the particles have the diameter in this range. In a similar way, in Figure 4b, it was observed that the average diameter of the particles belonging to sample 4 is $7.7 \mathrm{~nm}$ and $90 \%$ of these particles have sizes between 3 and 12 $\mathrm{nm}$. For sample 6 , the average diameter obtained was of 8.2 $\mathrm{nm}$ with standard deviation of $0.3 \mathrm{~nm}$. The calculated area in the range of 4 and $13 \mathrm{~nm}$ indicates that $90 \%$ of particles are in this range. These particle sizes have a close relation to the crystallite size obtained by Rietveld refinement and shown in Table 2.

In the titration curve there are two point of equivalence, the first one being at $\mathrm{pH} 5.9$ and the second one at $\mathrm{pH}$ 9.7. Based on these results, we showed that basic medium can provide the particle growth. Alkaline medium supports the formation of indium and tin hydroxide complex ${ }^{31}$, the mechanism related with this growth might be the olation, which consists in a solution process that transforms the complex ions in a polymeric oxide ${ }^{32}$. Increasing the $\mathrm{pH}$ of the solution, the complexation of the precursor ions become more effective and consequently the dimension of the polymeric clusters grew together, resulting in bigger particles.

The presence of organic molecules at materials surface was studied by ATR-FTIR. All organic bonds depicted in Figure 5 match with ethylene glycol absorption spectrum (peaks at $3216,2928,2880,1394,1079,1037$ and $880 \mathrm{~cm}^{-1}$ ), which was the precursor for obtaining ITO materials. Absorptions frequencies at 1661,1579 and $565 \mathrm{~cm}^{-1}$ belongs to metal chlorides ${ }^{33,34}$. FTIR results clearly shows that samples 3,4 and 8 present lower amount of residues. On the other hand, samples 5 and 7 exhibit higher amount of ethylene glycol due to the broad absorption peak at $3216 \mathrm{~cm}^{-1}$, corresponding to $\mathrm{OH}$ group. The smaller crystallite size presented by these samples can justifies the strongest functionalization. The higher amount of residues at samples 3 and 5 also explains both the broader peaks at XRD diffractograms and broader rings at $\mathrm{SAD}$ patterns.

In order to get the optical band gap of studied materials it was employed Kubelka-Munk method ${ }^{35}$ at UV-Vis reflectance results. The optical band gap was determined by the product of Kubelka-Munk quantity $\left(\mathrm{F}\left(\mathrm{R}_{\infty}\right)\right)$ and photon energy (ho) to the power of 2; where the exponent can assumes the values $2,2 / 3,1 / 2$ or $1 / 3$, depending on the nature of the electronic transition responsible for absorption mechanism 
${ }^{36}$. In Figure 6 it is possible to observe that the optical band gap of synthesized materials oscillate from $3.0 \mathrm{eV}$ to $3.4 \mathrm{eV}$. Although the band gaps are quite similar, according BursteinMoss effect an energy difference of $0.1 \mathrm{eV}$ can mean a raise in electronic density of $1.1 \cdot 10^{18} \cdot \mathrm{cm}^{-3} 37,38$. The particle size also affect the band gap, if it is smaller than Bohr radius of exciton the optical band gap increases, and this could explain the higher gap value observed for sample 5. Since $\mathrm{F}\left(\mathrm{R}_{\infty}\right)$ is related with the ratio between absorption/scattering coefficients we can affirms that all those samples are very transparent in visible spectrum (from $400 \mathrm{~nm}$ to $700 \mathrm{~nm}$ ), which is important for practical applications of materials.

\section{Conclusions}

A systematic study to obtain ITO nanoparticles by microwave assisted solvothermal method was performed in this work. The influence of the acid and basic precursor solution on the final structure, and morphological characteristics of collected materials was carefully studied. Results showed that materials in the ITO phase are obtained in a narrow range of $\mathrm{pHs}$, from 11.5 to 11.9. However, the mass of base used to reach the desired $\mathrm{pH}$ is enough to increase the particle size. Morphological characterization showed that ITO materials are composed of spherical nanoparticles. An olation mechanism was proposed to explain the oxide growth in alkaline environment. The transparency of the synthesized materials ranged from $85 \%$ to $95 \%$, and particle size between 3.4 and $8.2 \mathrm{~nm}$, enabling it to apply these materials in devices requiring high light transmittance. Results showed that microwave assisted solvothermal route is appropriate to obtain nanocrystalline ITO particles.

\section{Acknowledgement}

This work was supported by CNPq (proc \#485644/20118, \#309013/2012-7 and \#303542/2015-2) and Fapesp (proc \#2013/07296-2) agencies. SEM and TEM facilities were provided by LMA-IQ-UNESP.

\section{References}

1. Huang M, Hameiri Z, Venkataraj S, Aberle AG, Mueller T. Characterisation and Optimisation of Indium Tin Oxide Films Deposited by Pulsed DC Magnetron Sputtering for Heterojunction Silicon Wafer Solar Cell Applications. Energy Procedia. 2013;33:91-98. DOI: 10.1016/j.egypro.2013.05.044

2. Turgut G, Keskenler EF, Aydin S, Yilmaz M, Dogan S, Düzgün B. An investigation of the $\mathrm{Nb}$ doping effect on structural, morphological, electrical and optical properties of spray deposited F doped $\mathrm{SnO}_{2}$ films. Physica Scripta. 2013;87(3):035602. DOI: 10.1088/0031-8949/87/03/035602

3. Benouis CE, Benhaliliba M, Mouffak Z, Avila-Garcia A, TiburcioSilver A, Ortega Lopez M, et al. The low resistive and transparent Al-doped $\mathrm{SnO}_{2}$ films: p-type conductivity, nanostructures and photoluminescence. Journal of Alloys and Compounds. 2014;603:213-223. DOI: 10.1016/j.jallcom.2014.03.046

4. Dhamodharan P, Manoharan C, Bououdina M, Venkadachalapathy $\mathrm{R}$, Ramalingam $\mathrm{S}$. Al-doped $\mathrm{ZnO}$ thin films grown onto ITO substrates as photoanode in dye sensitized solar cell. Solar Energy. 2017;141:127-144. DOI: 10.1016/j.solener.2016.11.029.

5. Potter DB, Bhachu DS, Powell MJ, Darr JA, Parkin IP, Carmalt CJ. Al-, Ga-, and In-doped $\mathrm{ZnO}$ thin films via aerosol assisted CVD for use as transparent conducting oxides. physica status solidi A. 2016;213(5):1346-1352. DOI: 10.1002/pssa.201532996.

6. Chopra KL, Major S, Pandya DK. Transparent conductors-A status review. Thin Solid Films. 1983;102(1):1-46. DOI: 10.1016/0040-6090(83)90256-0

7. Baía I, Quintela M, Mendes L, Nunes P, Martins R. Performances exhibited by large area ITO layers produced by r.f. magnetron sputtering. Thin Solid Films. 1999;337(1-2):171-175. DOI: 10.1016/S0040-6090(98)01393-5

8. Hamberg I, Granqvist CG, Berggren KF, Sernelius BE, Engström L. Optical properties of transparent and infra-red-reflecting ITO films in the 0.2-50 $\mu \mathrm{m}$ range. Vacuum. 1985;35(6):207-209. DOI: $10.1016 / 0042-207 X(85) 90391-4$

9. Arlindo EPS, Lucindo JA, Bastos CMO, Emmel PD, Orlandi MO. Electrical and Optical Properties of Conductive and Transparent Ito@PMMA Nanocomposites. Journal of Physical Chemistry C. 2012;116(23):12946-12952. DOI: 10.1021/jp3031418.

10. Kim HW, Kim YI. Characteristics of Indium-Tin-Oxide Nanoparticles Prepared by Controlled Chemical Coprecipitation Method. Bulletin of the Korean Chemical Society. 2008;29(9):18271830. DOI: $10.5012 /$ bkcs.2008.29.9.1827

11. Yu D, Wang D, Yu W, Qian Y. Synthesis of ITO nanowires and nanorods with corundum structure by a co-precipitation-anneal method. Materials Letters. 2004;58(1-2):84-87. DOI: 10.1016/ S0167-577X(03)00420-8

12. Orlandi MO, Aguiar R, Lanfredi AJC, Longo E, Varela JA, Leite ER. Tin-doped indium oxide nanobelts grown by carbothermal reduction method. Applied Physics A. 2005;80(1):23-25. DOI: 10.1007/s00339-004-3027-x

13. Bühler G, Thölmann D, Feldmann C. One-Pot Synthesis of Highly Conductive Indium Tin Oxide Nanocrystals. Advanced Materials. 2007;19(17):2224-2227. DOI: 10.1002/adma.200602102

14. Ba J, Rohlfing DF, Feldhoff A, Brezesinski T, Djerdj I, Wark $\mathrm{M}$, et al. Nonaqueous Synthesis of Uniform Indium Tin Oxide Nanocrystals and Their Electrical Conductivity in Dependence of the Tin Oxide Concentration. Chemistry of Materials. 2006;18(12):2848-2854. DOI: $10.1021 / \mathrm{cm} 060548 \mathrm{q}$

15. Li ZH, Ren DY. Preparation of ITO transparent conductive film by sol-gel method. Transactions of Nonferrous Metals Society of China. 2006;16(6):1358-1361. DOI: 10.1016/S10036326(07)60020-X

16. Lee I, Lee SY. Growth of Conductive Indium Tin Oxide (ITO) Nanoparticles by Mineralization in Ring-Shaped Biomimetic Templates. Journal of Physical Chemistry C. 2009;113(40):1737217377. DOI: $10.1021 /$ jp $905869 b$ 
17. Fukui K, Kanayama K, Katoh M, Yamamoto T, Yoshida H. Synthesis of indium tin oxide powder by solid-phase reaction with microwave heating. Advanced Powder Technology. 2009;20(5):488-492. DOI: 10.1016/j.apt.2009.05.007

18. Okuya M, Ito N, Shiozaki K. ITO thin films prepared by a microwave heating. Thin Solid Films. 2007;515(24):8656-8659. DOI: $10.1016 /$ j.tsf.2007.03.148

19. Mingos DMP, Baghurst DR. Tilden Lecture. Applications of microwave dielectric heating effects to synthetic problems in chemistry. Chemical Society Reviews. 1991;20(1):1-47. DOI: $10.1039 / \mathrm{CS} 9912000001$

20. Hayes BL. Microwave Synthesis: Chemistry at the Speed of Light. $1^{\text {st }}$ ed. Matthew: CEM Publishing; 2002.

21. Schanche JS. Microwave synthesis solutions from personal chemistry. Molecular Diversity. 2003;7(2-4):291-298. DOI: 10.1023/B:MODI.0000006866.38392.f7

22. Van Noorden R. Microwaving myths. Chemistry World;2008. Available from: $<$ https://www.chemistryworld.com/feature/microwavingmyths/3004691.article\#commentsJump $>$. Access in: 15/12/2017.

23. Maksimov VD, Meskin PE, Churagulov BR. Hydrothermalmicrowave synthesis of fine disperse powders of simple and complex zirconium and hafnium oxides. Journal of Surface Investigation. X-ray, Synchrotron and Neutron Techniques. 2008;2(1):146-151. DOI: 10.1007/s11700-008-1023-z

24. Keyson D, Volanti DP, Cavalcante LS, Simões AZ, Souza IA, Vasconcelos JS, et al. Domestic microwave oven adapted for fast heat treatment of $\mathrm{Ba}_{0.5} \mathrm{Sr}_{05}\left(\mathrm{Ti}_{0.8} \mathrm{Sn}_{02}\right) \mathrm{O}_{3}$ powders. Journal of Materials Processing Technology. 2007;189(1-3):316-319. DOI: $10.1016 /$ j.jmatprotec.2007.02.001

25. Hammarberg E, Prodi-Schwab A, Feldmann C. Microwaveassisted synthesis of indium tin oxide nanocrystals in polyol media and transparent, conductive layers thereof. Thin Solid Films. 2008;516(21):7437-7442. DOI: 10.1016/j.tsf.2008.02.048

26. Kim SM, Seo KH, Lee JH, Kim JJ, Lee HY, Lee JS. Preparation and sintering of nanocrystalline ITO powders with different $\mathrm{SnO}_{2}$ content. Journal of the European Ceramic Society. 2006;26(12):73-80. DOI: 10.1016/j.jeurceramsoc.2004.10.009

27. Choi SI, Nam KM, Park BK, Seo WS, Park JT. Preparation and Optical Properties of Colloidal, Monodisperse, and Highly Crystalline ITO Nanoparticles. Chemistry of Materials. 2008;20(8):2609-2611. DOI: 10.1021/cm703706m

28. Xu H, Zhu G, Zhou H, Yu A. Preparation of Monodispersed Tin-Doped Indium Oxide Powders by Hydrothermal Method. Journal of the American Ceramic Society. 2005;88(4):986-988. DOI: $10.1111 / \mathrm{j} .1551-2916.2005 .00158 . x$
29. Toby BH, Von Dreele RB. GSAS-II : the genesis of a modern open-source all purpose crystallography software package. Journal of Applied Crystallography. 2013;46:544-549. DOI: $10.1107 / \mathrm{S} 0021889813003531$

30. González GB, Mason TO, Quintana JP, Warschkow O, Ellis $\mathrm{DE}$, Hwang JH, et al. Defect structure studies of bulk and nanoindium-tin oxide. Journal of Applied Physics. 2004;96(7):39123920. DOI: $10.1063 / 1.1783610$

31. Daido T, Akaike T. Electrochemistry of cytochrome c: influence of coulombic attraction with indium tin oxide electrode. Journal of Electroanalytical Chemistry. 1993;344(1-2):91-106. DOI: 10.1016/0022-0728(93)80048-M

32. Wilberg N, Holleman AF, Wiberg E. Holleman-Wiberg's Inorganic Chemistry. $1^{\text {st }}$ ed. San Diego: Academic Press; 2001.

33. Vieira L, Schennach R, Gollas B. In situ PM-IRRAS of a glassy carbon electrode/deep eutectic solvent interface. Physical Chemistry Chemical Physics. 2005;17(19):12870-12880. DOI: 10.1039/C5CP00070J

34. Socrates G. Infrared Characteristic Group Frequencies: Tables and Charts. $2^{\text {nd }}$ ed. New York: John Wiley \& Sons; 1994.

35. Nobbs JH. Kubelka-Munk Theory and the Prediction of Reflectance. Coloration Technology. 1985;15(1):66-75. DOI: 10.1111/j.1478-4408.1985.tb03737.x

36. Sabino FP, Nunes Oliveira L, Wei SH, Da Silva JL. Optical and fundamental band gaps disparity in transparent conducting oxides: new findings for the $\mathrm{In}_{2} \mathrm{O}_{3}$ and $\mathrm{SnO}_{2}$ systems. Journal of Physics: Condensed Matter. 2017;29(8):085501. DOI: 10.1088/1361-648X/aa4e8c

37. Burstein E. Anomalous Optical Absorption Limit in InSb. Physical Review. 1954;93(3):632-633. DOI: 10.1103/PhysRev.93.632

38. Moss TS. The interpretation of the Properties of Indium Antimonide. Proceedings of the Physical Society. Section B. 1954;67(10):775-778. DOI: 10.1088/0370-1301/67/10/306

\section{Supplementary material}

The following online material is available for this article:

Figure S1 - Photo of powders synthesized in distinct pHs. The numbers in the images are related to the Table 1 nomenclature.

Figure S2 - FEG-SEM images from samples 3, 4, 5, 6 and 7 which are respectively depicted by Figure a), b), c), d) and e). 